\title{
Peroxidase-Like Platinum Clusters Synthesized by Ganoderma lucidum Polysaccharide for Sensitively Colorimetric Detection of Dopamine
}

\author{
Xiang Lai ${ }^{1}$, Yu Han ${ }^{1}$, Jie Zhang ${ }^{1}$, Jinyu Zhang ${ }^{1}$, Weifeng Lin ${ }^{2}$, Zhiwei Liu ${ }^{1}$ and Longgang Wang ${ }^{1, *}$ \\ 1 Key Laboratory of Applied Chemistry, Hebei Key Laboratory of Heavy Metal Deep-Remediation in Water \\ and Resource Reuse, College of Environmental and Chemical Engineering, Yanshan University, \\ Qinhuangdao 066004, China; 1x0406x@163.com (X.L.); hy1201024@126.com (Y.H.); \\ 19991641458@163.com (J.Z.); 15032376798@163.com (J.Z.); zwliu@ysu.edu.cn (Z.L.) \\ 2 Department of Molecular Chemistry and Materials Science, Weizmann Institute of Science, \\ Rehovot 76100, Israel; lin.weifeng@weizmann.ac.il \\ * Correspondence: lgwang@ysu.edu.cn
}

check for updates

Citation: Lai, X.; Han, Y.; Zhang, J.; Zhang, J.; Lin, W.; Liu, Z.; Wang, L. Peroxidase-Like Platinum Clusters Synthesized by Ganoderma lucidum Polysaccharide for Sensitively Colorimetric Detection of Dopamine. Molecules 2021, 26, 2738.

https://doi.org/10.3390/

molecules26092738

Academic Editor: Cédric Delattre

Received: 13 April 2021

Accepted: 4 May 2021

Published: 6 May 2021

Publisher's Note: MDPI stays neutral with regard to jurisdictional claims in published maps and institutional affiliations.

Copyright: (c) 2021 by the authors. Licensee MDPI, Basel, Switzerland. This article is an open access article distributed under the terms and conditions of the Creative Commons Attribution (CC BY) license (https:// creativecommons.org/licenses/by/ $4.0 /)$.

\begin{abstract}
The sensitive and selective detection of dopamine (DA) is very important for the early diagnosis of DA-related diseases. In this study, we reported the colorimetric detection of DA using Ganoderma lucidum polysaccharide (GLP) stabilized platinum nanoclusters ( $\mathrm{Pt}_{\mathrm{n}}$-GLP NCs). When $\mathrm{Pt}_{600}$-GLP NCs was added, 3,3',5,5'-tetramethylbenzidine (TMB) was rapidly catalyzed and oxidized to blue oxTMB, indicating the peroxidase-like activity of $\mathrm{Pt}_{600}$-GLP NCs. The catalytic reaction on the substrate TMB followed the Michaelis-Menton kinetics with the ping-pong mechanism. The mechanism of the colorimetric reaction was mainly due to the formation of hydroxyl radical $(\bullet \mathrm{OH})$. Furthermore, the catalytic reaction of $\mathrm{Pt}_{600}$-GLP NCs was used in the colorimetric detection of DA. The linear range for DA was $1-100 \mu \mathrm{M}$ and the detection limit was $0.66 \mu \mathrm{M}$. The sensitive detection of DA using Pt-GLP NCs with peroxidase-like activity offers a simple and practical method that may have great potential applications in the biotechnology field.
\end{abstract}

Keywords: dopamine; detection; platinum; colorimetric; Ganoderma lucidum polysaccharide

\section{Introduction}

As we all know, dopamine (DA) is an important catecholamine neurotransmitter in the nervous system, which plays a key role in human metabolism. Abnormal levels of dopamine in body fluids can cause various neurological diseases, such as schizophrenia or Parkinson's disease [1]. Moreover, it has profound significance to control DA at a level suitable for the normal activities of human cells [2]. Therefore, accurate and convenient detection of DA is an important and valuable work in the field of biology. To date, many different methods have been developed to detect DA, including fluorescence [3], electrochemistry [4], and colorimetric methods [5]. It is worth noting that colorimetric methods have always attracted attention due to its simple operation and visual observation. In recent years, some substances with peroxidase-like properties have been considered to be essential in colorimetric sensor platforms. It overcomes the shortcomings of natural horseradish peroxidase (HRP), such as high cost, poor stability, difficult preparation, and storage. Therefore, this kind of artificial peroxidase has been widely studied.

A variety of substances with peroxidase-like properties sprung up like mushrooms, from noble metal nanoparticles [6], metal oxides [7], to multi-metal compounds [8]. This peroxidase-like activity of nanozymes has been used in colorimetry to detect many biologically related substances, such as $\mathrm{H}_{2} \mathrm{O}_{2}$ [9], glucose [10], DA [11], and glutathione [12]. While great progress has been made, there are still some difficulties and challenges in the study of nanozymes. Compared with other artificial enzymes, they have poor stability, low activity, and biocompatibility. Therefore, it is very much expected to explore 
chemically stable and environmentally friendly nanozymes as simulants in bioassays and disease diagnosis.

Platinum is an important element in chemical industries. Nanozymes for platinum have been extensively studied because of their enzyme-like activities [13], but their preparation still faces challenges. The preparation usually uses some harmful materials, such as carcinogenic polymer materials [14] and flammable chemical reducing agent $\mathrm{NaBH}_{4}$ [15]. In addition, there are problems in controlling the size and structure of nanozymes [16,17]. Many reported Pt nanomaterials have relatively large particle sizes, which means a small specific surface area and relatively low atom utilization $[18,19]$. They are thermodynamically unbalanced and tend to aggregate during chemical reactions, resulting in a loss of activity. Consequently, controlling the shape, size and dispersion of nanoparticles is the key factor in achieving high stability and activity. Recently, polysaccharide as a green biomaterial has attracted people's attention, which is widely used as a carrier material due to its good biocompatibility [10]. Ganoderma lucidum polysaccharide (GLP) is the active component extracted from Ganoderma lucidum, and it is a natural biological macromolecule. It has beneficial physiological functions in immune regulation, anti-tumor, antioxidation, hypoglycemia, and regulation of intestinal health, so it has received extensive attention [20-22]. The biological activity of GLP is correlated with its composition, threedimensional structure, and helical conformation [20]. GLP contains $\beta-(1 \rightarrow 6)-, \beta-(1 \rightarrow 4)-$, and $\beta-(1 \rightarrow 3)$-D-glucopyranosyl residues in the backbone and sidechains [23]. Moreover, there are many active groups in the structure of GLP, such as hydroxyl and carboxyl, so it can be easily chemically and biochemically modified [20,24]. GLP has high biocompatibility, so it is an ideal material for green preparation of platinum-based nanozymes.

In this work, we prepared GLP-stabilized Pt nanoclusters ( $\mathrm{Pt}_{\mathrm{n}}$-GLP NCs), where GLP was used as a stabilizer and reducing agent. $\mathrm{Pt}_{\mathrm{n}}-\mathrm{GLP}$ NCs had a small size for Pt nanoclusters (Pt NCs) and peroxidase-like activity. GLP protected the wrapped nanoparticles from aggregation, resulting in particles with higher stability. To demonstrate the practical application of $\mathrm{Pt}_{\mathrm{n}}$-GLP NCs, we utilized the peroxidase-like activity of the nanozyme to develop a colorimetric method for the visual and sensitive detection of dopamine (Scheme 1). This method has the potential for the development of bio-related detection of actual samples.

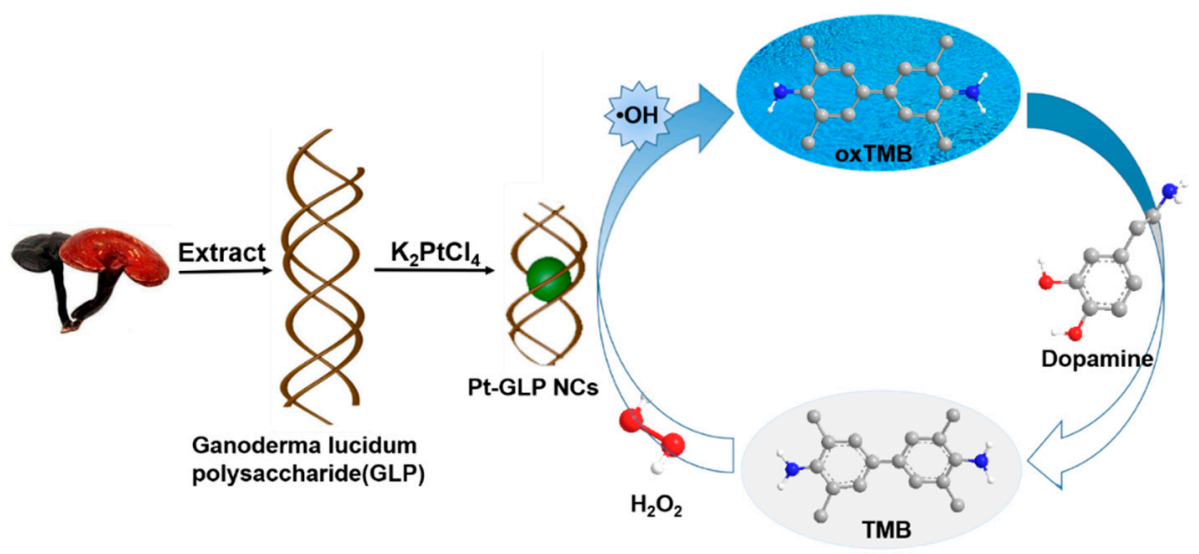

Scheme 1. The synthesis of Pt-GLP NCs and the schematic diagram of dopamine detection.

\section{Results and Discussion}

\subsection{Structure Characterizations}

Natural plant polysaccharides are formed by various monosaccharides with glycosidic linkages. Plant polysaccharides also have high molecular weight and various biological activities. GLP is a functional substance obtained from Ganoderma and a potent clinical agent [25]. We used GPC to determine the relative molecular weight of polysaccharides, and the results are shown in Figure 1a. The $\mathrm{M}_{\mathrm{w}}$ of GLP was $1.77 \times 10^{5} \mathrm{~g} \mathrm{~mol}^{-1}$, and the $\mathrm{M}_{\mathrm{n}}$ was $1.70 \times 10^{5} \mathrm{~g} \mathrm{~mol}^{-1}$. The polydispersity coefficient of GLP was calculated by $\mathrm{M}_{\mathrm{w}} / \mathrm{M}_{\mathrm{n}}=1.0412$, indicating that GLP was a narrowly distributed polydisperse system [26]. 

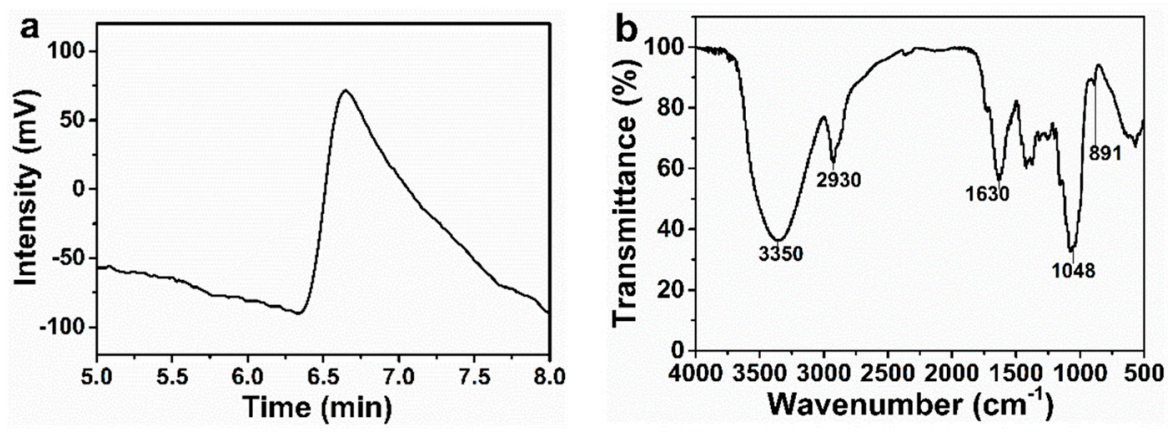

Figure 1. (a) GPC determination and (b) infrared spectrum of GLP.

The FTIR spectrum of GLP was further measured. Due to the hydroxyl stretching vibration, Figure $1 \mathrm{~b}$ shows a broad stretching peak at $3350 \mathrm{~cm}^{-1}$, while for the $\mathrm{C}-\mathrm{H}$ stretching vibration, it shows weak absorption at $2930 \mathrm{~cm}^{-1}$. The absorbance at $1630 \mathrm{~cm}^{-1}$ indicated the presence of a carbonyl group. In addition, the main absorption of $\mathrm{C}-\mathrm{O}$ stretching $\left(1048 \mathrm{~cm}^{-1}\right)$ indicated that the structure of the sugar was pyranose configuration. Moreover, the band at $891 \mathrm{~cm}^{-1}$ was the characteristic absorption of $\beta$-linkage of pyranose [27].

As shown in Figure 2a, the standard curve of protein content was measured by the Coomassie Brilliant Blue method. The equation was $y=0.561 x+0.347$. The result showed that the purity of the polysaccharide was about $92 \%$. GLP can reduce potassium ferricyanide to potassium ferrocyanide, and ferrous ions can react with ferric chloride to produce Prussian blue, which has a maximum absorption peak at $700 \mathrm{~nm}$. Thus, the reducing ability of GLP was determined by this method. As shown in Figure $2 b$, the absorbance at $700 \mathrm{~nm}$ increased with the increasing concentration of GLP. When the concentration of GLP reached $2 \mathrm{mg} / \mathrm{mL}$, the corresponding absorbance reached 0.459 . This indicated that the reducing ability of GLP increased with the increase of concentration of GLP. The reducing ability of GLP was attributed to a large number of hydroxyl and aldehyde groups of GLP, which is a chain compound with a triple-helical structure [20].
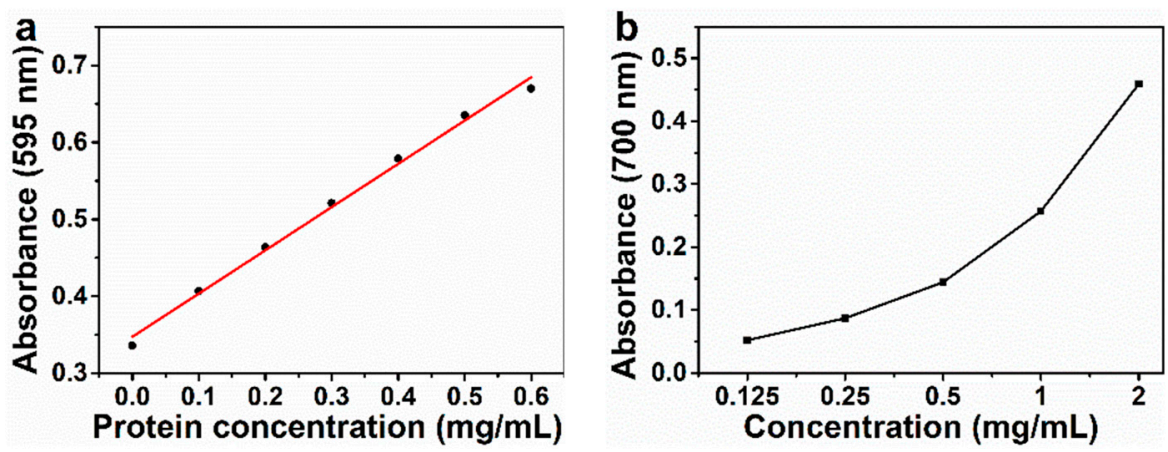

Figure 2. (a) The protein content standard curve at $595 \mathrm{~nm}$ and (b) the reducing ability curve of GLP at $700 \mathrm{~nm}$.

The high purity and reducing ability of GLP were beneficial to the generation of noble metal nanomaterials [20]. In this study, Pt NCs were prepared by incubating GLP with $\mathrm{K}_{2} \mathrm{PtCl}_{4}$. As shown in Figure 3, $\mathrm{K}_{2} \mathrm{PtCl}_{4}$ showed a characteristic absorption peak at $390 \mathrm{~nm}$. After $\mathrm{K}_{2} \mathrm{PtCl}_{4}$ and GLP were incubated for $12 \mathrm{~h}$, the absorption peak of $\mathrm{K}_{2} \mathrm{PtCl}_{4}$ solution at $390 \mathrm{~nm}$ disappeared, indicating that $\mathrm{Pt}^{2+}$ was reduced to $\mathrm{Pt}^{0}$ by GLP. Compared with the use of traditional chemical reducing agents such as $\mathrm{NaBH}_{4}$, the use of GLP was greener and the reaction was milder. 


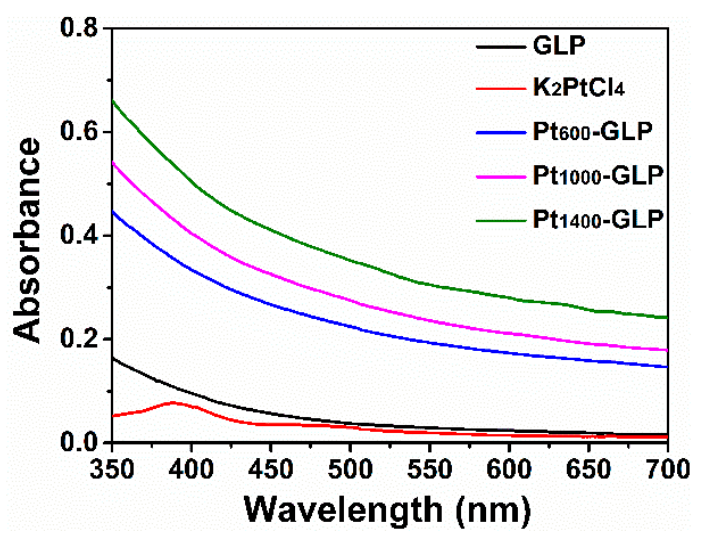

Figure 3. UV-Vis spectra of GLP, $\mathrm{K}_{2} \mathrm{PtCl}_{4}$, and $\mathrm{Pt}_{\mathrm{n}}$-GLP NCs $(\mathrm{n}=600,1000$, and 1400).

Metal nanoparticles exhibit unique physical and chemical properties due to their small size and large specific surface area. In general, smaller particles show better catalytic efficiency, because smaller nanoparticles possess a larger surface-to-volume ratio [28]. Here, the size of Pt NCs inside Pt $\mathrm{t}_{60}$-GLP NCs was measured by HRTEM. As shown in Figure 4, the Pt NCs inside $\mathrm{Pt}_{600}$-GLP NCs existed in a good monodisperse state, and the calculated average diameter of Pt NCs inside $\mathrm{Pt}_{600}-\mathrm{GLP}$ NCs was $1.44 \pm 0.34 \mathrm{~nm}$. Supplementary Materials Figure $\mathrm{S} 1$ showed that the Pt NCs inside Pt $\mathrm{Pt}_{600}-\mathrm{GLP}$ NCs and $\mathrm{Pt}_{1000}-\mathrm{GLP}$ NCs had a good dispersion state, respectively. The size of $\mathrm{Pt}$ NCs inside $\mathrm{Pt}_{1000}$-GLP NCs and $\mathrm{Pt}_{1400^{-}}$ GLP NCs were $2.12 \pm 0.72 \mathrm{~nm}$ and $2.34 \pm 0.54 \mathrm{~nm}$, respectively. These results indicated that Pt NCs inside $\mathrm{Pt}_{\mathrm{n}}$-GLP NCs had a small size within 1-3 nm and narrow size distribution, which may be contributed by the mild reducing ability of GLP [29]. The specific surface area of the nanoparticles was calculated by the surface area and volume method, and the specific surface area was $4.41 \pm 1.46 \mathrm{~nm}^{2} / \mathrm{nm}^{3}$ for $\mathrm{Pt}_{600}$-GLP NCs, $3.20 \pm 1.54 \mathrm{~nm}^{2} / \mathrm{nm}^{3}$ for $\mathrm{Pt}_{1000}$-GLP NCs, and $2.59 \pm 0.71 \mathrm{~nm}^{2} / \mathrm{nm}^{3}$ for $\mathrm{Pt}_{1400}$-GLP NCs. Thus, $\mathrm{Pt}_{600}$-GLP NCs had the largest specific surface area, and they were used for subsequent experiments.
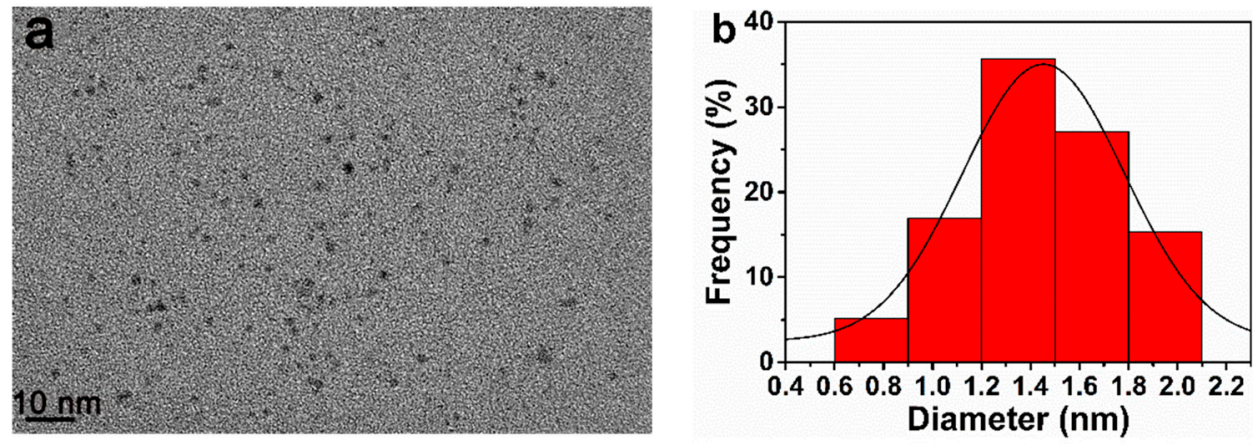

Figure 4. (a) HRTEM image and (b) histogram of $\mathrm{Pt}_{600}-\mathrm{GLP}$ NCs.

The hydrodynamic size and zeta potential of $\mathrm{Pt}_{\mathrm{n}}$-GLP NCs were measured using DLS technology [30]. As shown in Figure 5a, the hydrodynamic size was $17.63 \pm 1.45 \mathrm{~nm}$ for $\mathrm{Pt}_{600}$-GLP NCs, $18.18 \pm 0.03 \mathrm{~nm}$ for $\mathrm{Pt}_{1000}$-GLP NCs, and $19.61 \pm 2.87 \mathrm{~nm}$ for $\mathrm{Pt}_{1400}$-GLP $\mathrm{NCs}$, respectively. The hydrodynamic size of $\mathrm{Pt}_{\mathrm{n}}$-GLP NCs included the GLP molecule, which was much bigger than the size of Pt NCs as measured using TEM. Furthermore, the zeta potential of $\mathrm{Pt}_{\mathrm{n}}$-GLP NCs was also measured in water. GLP is a chain compound with a triple-helical structure. Figure $5 \mathrm{~b}$ shows that the zeta potential was $-12.93 \pm 2.59 \mathrm{mV}$ for $\mathrm{Pt}_{600}$-GLP NCs, $-15.1 \pm 1.37 \mathrm{mV}$ for $\mathrm{Pt}_{1000}$-GLP NCs, and $-14.08 \pm 1.15 \mathrm{mV}$ for $\mathrm{Pt}_{1400}$-GLP $\mathrm{NCs}$, respectively. Thus, $\mathrm{Pt}_{\mathrm{n}}$-GLP NCs had a hydrodynamic size from 17.6 to $19.6 \mathrm{~nm}$ and a slightly negative charge [29]. 

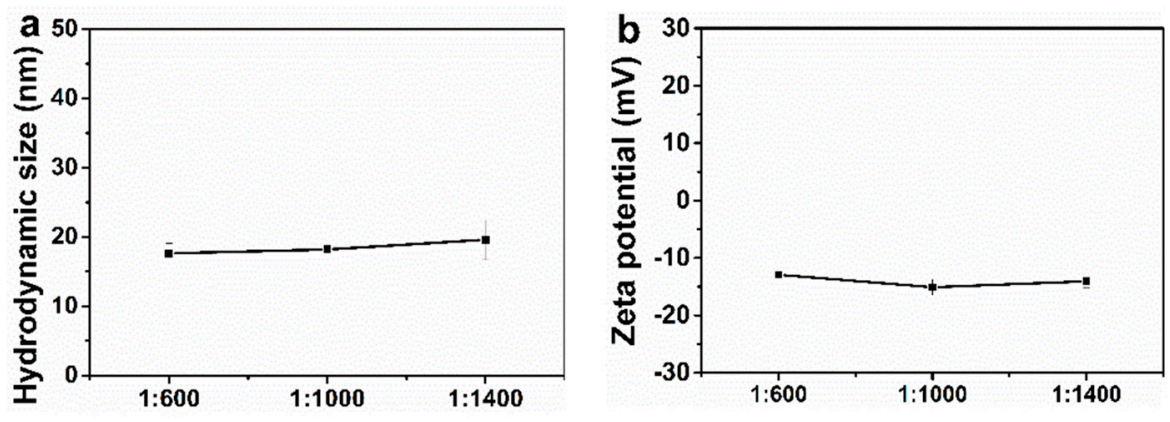

Figure 5. (a) The hydrodynamic size and (b) zeta potential of $\mathrm{Pt}_{\mathrm{n}}$-GLP NCs in aqueous solution.

\subsection{Peroxidase-Like Activity}

The peroxidase-like activity of $\mathrm{Pt}_{600}-\mathrm{GLP}$ NCs was studied using TMB as the substrate in the presence of $\mathrm{H}_{2} \mathrm{O}_{2}$. As shown in Figure $6 \mathrm{a}$, the TMB $+\mathrm{H}_{2} \mathrm{O}_{2}+\mathrm{Pt}_{600}$-GLP NCs group had the maximum absorption peak at $652 \mathrm{~nm}$, and the sample of this group corresponded to a clear blue solution (Figure 6b). Conversely, in the absence of $\mathrm{H}_{2} \mathrm{O}_{2}$ or $\mathrm{Pt}_{600}-\mathrm{GLP} N C s$, the color of the solution did not change. Therefore, these results demonstrated that $\mathrm{Pt}_{\mathrm{n}}$ GLP NCs had peroxidase-like activity. Other noble metal nanoparticles, such as platinum nanoparticles [10] and rhodium nanoparticles [31], have also been reported, exhibiting peroxidase-like activity.
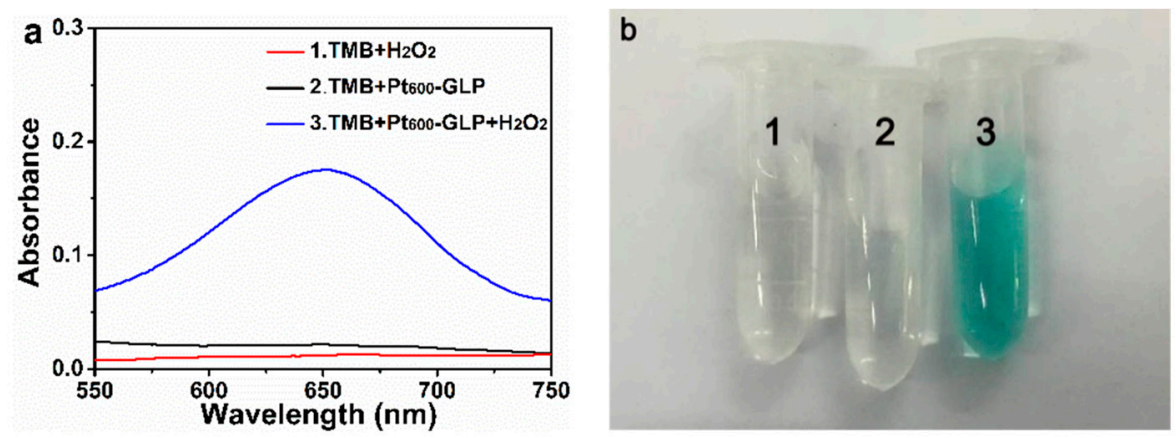

Figure 6. (a) UV-Vis spectra and (b) picture of the reaction product: (1) TMB $+\mathrm{H}_{2} \mathrm{O}_{2}$, (2) TMB + $\mathrm{Pt}_{600}$-GLP NCs, and (3) TMB + $\mathrm{Pt}_{600}-\mathrm{GLP} \mathrm{NCs}+\mathrm{H}_{2} \mathrm{O}_{2}$. Concentrations: TMB, $0.6 \mathrm{mM} ; \mathrm{Pt}, 0.78 \mathrm{mM}$; $\mathrm{H}_{2} \mathrm{O}_{2}, 0.3 \mathrm{M}$.

To optimize the reaction conditions, the effects of temperature and $\mathrm{pH}$ on the catalytic activity were further investigated. As shown in Figure 7a, the relative catalytic activity of $\mathrm{Pt}_{600}-\mathrm{GLP}$ NCs reached the highest when the temperature was $50{ }^{\circ} \mathrm{C}$, which was optimal for the reaction. The relative activity of $\mathrm{Pt}_{600}-\mathrm{GLP}$ NCs between 30 and $70{ }^{\circ} \mathrm{C}$ was above $50 \%$. Similarly, Figure $7 \mathrm{~b}$ showed that the optimal $\mathrm{pH}$ for $\mathrm{Pt}_{600}-\mathrm{GLP}$ NCs was 4.0. The optimal $\mathrm{pH}$ was consistent with the optimal activity of nanozymes reported by $\mathrm{Wu}$ et al. [32]. The optimum temperature and $\mathrm{pH}$ were correlated with the activity of $\mathrm{H}_{2} \mathrm{O}_{2}$. The optimal conditions were temperature $50^{\circ} \mathrm{C}$ and $\mathrm{pH} 4.0$, which were used for subsequent experiments. 

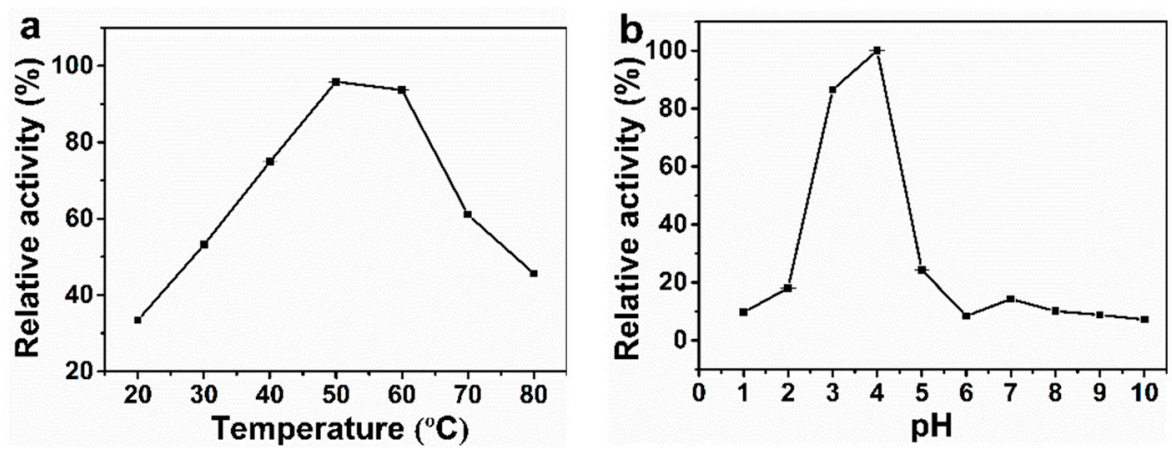

Figure 7. Effects of (a) temperature and (b) $\mathrm{pH}$ on the peroxidase-like property of $\mathrm{Pt}_{600}$-GLP NCs.

\subsection{Steady-State Kinetic}

The catalytic activity of $\mathrm{Pt}_{600}-\mathrm{GLP}$ NCs was investigated based on enzyme kinetics theory methods with $\mathrm{H}_{2} \mathrm{O}_{2}$ and TMB as substrates. A range of kinetic data was determined by changing the concentration of $\mathrm{H}_{2} \mathrm{O}_{2}$ or TMB. Figure $8 \mathrm{a}, \mathrm{b}$ are consistent with the Michaelis-Menten equation for TMB and $\mathrm{H}_{2} \mathrm{O}_{2}$, respectively. The apparent steadystate kinetic parameters $V_{\max }$ and $K_{m}$ were obtained using the Lineweaver-Burk plots, as shown in Table 1 . The $K_{m H 2 O 2}(2.06 \mathrm{mM})$ and $K_{m T M B}(0.17 \mathrm{mM})$ of $\mathrm{Pt}_{600}-\mathrm{GLP}$ NCs with substrates were both lower than the $K_{m}$ value corresponding to HRP. These data indicated a greater affinity between $\mathrm{Pt}_{600}$-GLP NCs and the substrate. As shown in Figure 8c, d, several parallel ramp data lines conformed to the characteristics of a ping-pong mechanism. The kinetic mechanism of $\mathrm{Pt}_{600}-\mathrm{GLP}$ NCs was in accordance with the enzyme-catalyzed ping-pong mechanism.
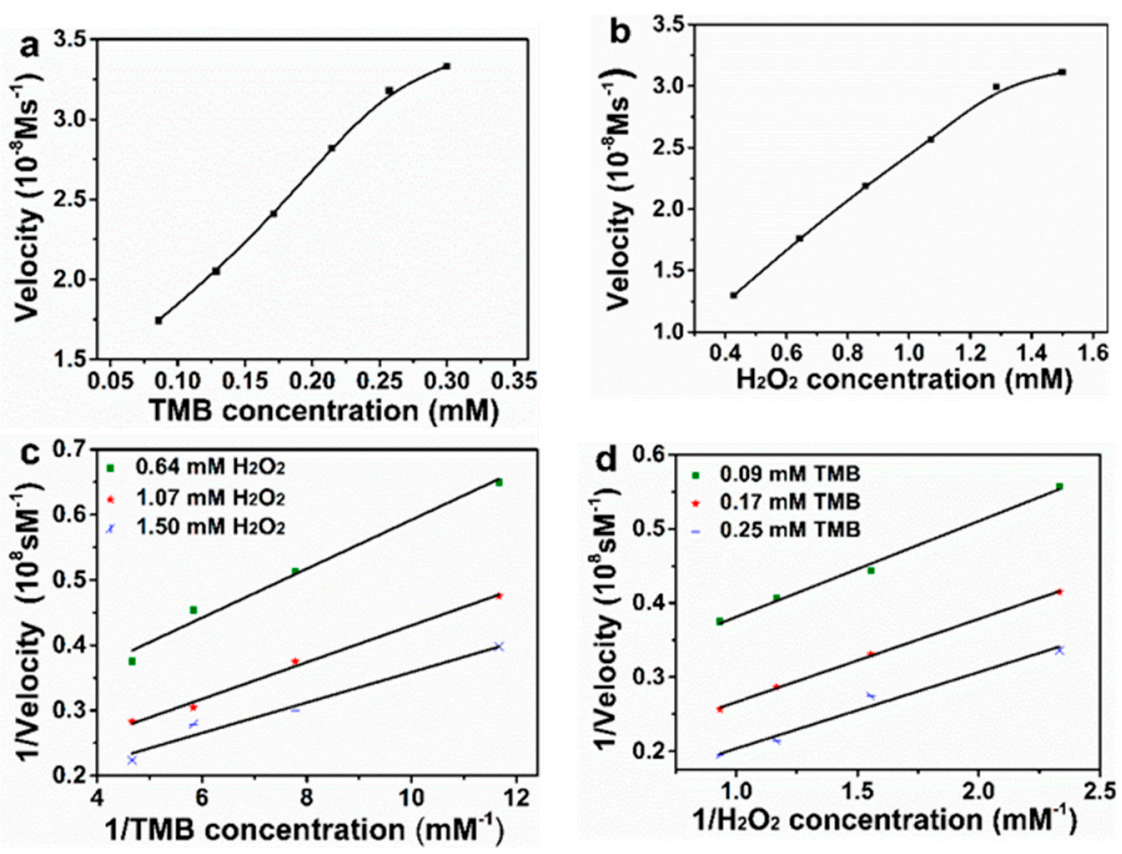

Figure 8. Steady-state kinetic assay and catalytic mechanism of $\mathrm{Pt}_{600}-\mathrm{GLP}$ NCs: (a) $\mathrm{The}_{2} \mathrm{H}_{2}$ was $1.07 \mathrm{mM}$ with varying TMB concentration. (b) The TMB was $0.17 \mathrm{mM}$ with varying $\mathrm{H}_{2} \mathrm{O}_{2}$ concentration. (c,d) Double reciprocal plots of activity of $\mathrm{Pt}_{600}$-GLP NCs with the concentration of one substrate $\left(\mathrm{H}_{2} \mathrm{O}_{2}\right.$ or TMB) fixed and the other varied. 
Table 1. Comparison of the kinetic parameters of $\mathrm{Pt}_{600}-\mathrm{GLP}$ NCs and HRP.

\begin{tabular}{ccccc}
\hline Catalyst & Substrate & $\boldsymbol{K}_{m} \mathbf{( m M )}$ & $V_{\max }\left(\mathbf{1 0}^{-\mathbf{8}} \mathbf{M ~ s}^{-\mathbf{1}}\right)$ & Reference \\
\hline $\mathrm{Pt}_{600}-\mathrm{GLP} N C s$ & $\mathrm{TMB}$ & 0.17 & 5.04 & this work \\
$\mathrm{Pt}_{600}-\mathrm{GLP} N C s$ & $\mathrm{H}_{2} \mathrm{O}_{2}$ & 2.06 & 7.51 & [33] \\
\hline $\mathrm{HRP}$ & $\mathrm{TMB}$ & 0.434 & 10.00 & 8.71 \\
$\mathrm{HRP}$ & $\mathrm{H}_{2} \mathrm{O}_{2}$ & 3.70 & & \\
\hline
\end{tabular}

\subsection{Catalytic Mechanism}

The enzymatic reaction mechanism may involve the decomposition of $\mathrm{H}_{2} \mathrm{O}_{2}$, which will generate $\bullet \mathrm{OH}$ radicals in the reaction system. To confirm this hypothesis, the formation of $\bullet \mathrm{OH}$ radicals was evaluated by using terephthalic acid (TA) as a fluorescent probe, where the TA easily reacted with $\bullet \mathrm{OH}$ to form highly fluorescent 2-hydroxyterephthalic acid. As shown in Figure 9, the system TA $+\mathrm{H}_{2} \mathrm{O}_{2}+\mathrm{Pt}_{600}$-GLP NCs generated the highest peak at $435 \mathrm{~nm}$ and the largest amount of $\bullet \mathrm{OH}$. The fluorescence intensity of the system TA + $\mathrm{H}_{2} \mathrm{O}_{2}+\mathrm{Pt}_{600}$-GLP NCs reached 7351. $\mathrm{Pt}_{600}$-GLP cannot effectively promote TA oxidation in the absence of $\mathrm{H}_{2} \mathrm{O}_{2}$. In addition, the $\mathrm{TA}+\mathrm{H}_{2} \mathrm{O}_{2}$ system produced a small amount of - $\mathrm{OH}$ and its corresponding fluorescence intensity was 1227. Other systems were much lower than that of the TA $+\mathrm{H}_{2} \mathrm{O}_{2}+\mathrm{Pt}_{600}$-GLP NCs system. The high fluorescence intensity indicated that the peroxidase-like activity of $\mathrm{Pt}_{600}$-GLP NCs was achieved by $\bullet \mathrm{OH}$ radical mechanism. The results were similar to the previous results of Ivanova et al. [11]. The intrinsic peroxidase activity of Pt-GLP NCs was mainly derived from Pt NCs [34], rather than the GLP. Thus, these results confirm the generation of $\bullet \mathrm{OH}$ radicals catalyzed by $\mathrm{Pt}_{600}$-GLP NCs, and $\bullet \mathrm{OH}$ radicals were the main reactive species in the peroxidase-like enzymatic reaction.
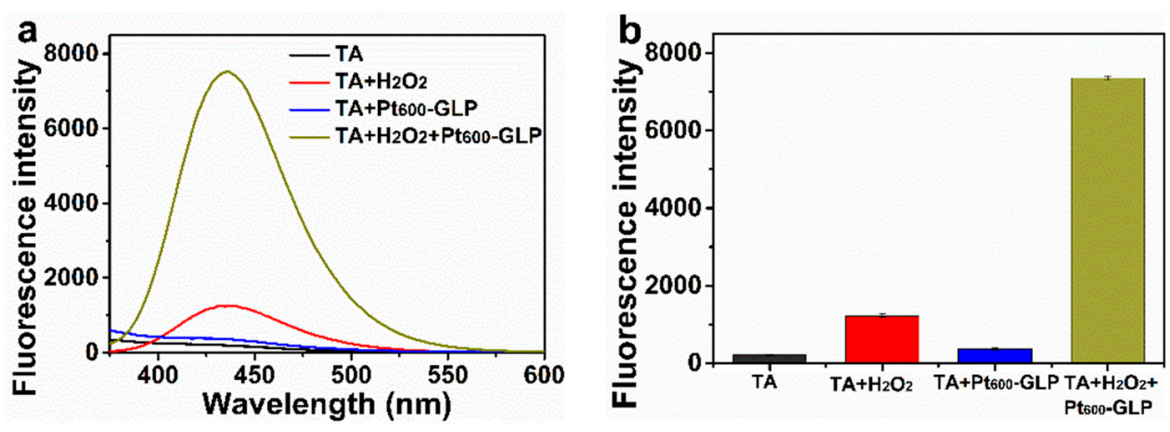

Figure 9. (a) Fluorescence spectra and (b) histograms of fluorescence intensity of $\mathrm{TA}+\mathrm{H}_{2} \mathrm{O}_{2}+$ $\mathrm{Pt}_{600}$-GLP NCs group and control groups after $12 \mathrm{~h}$. The final concentrations of $\mathrm{TA}, \mathrm{H}_{2} \mathrm{O}_{2}$, and $\mathrm{Pt}$ were $0.3 \mathrm{mM}, 20 \mathrm{mM}$, and $49 \mu \mathrm{M}$, respectively.

\subsection{Detection of Dopamine}

Dopamine (DA) is involved in many neural processes, and the concentration of dopamine is an important signal indirectly reflecting the health status of organisms. We applied a colorimetric method to detect dopamine based on the peroxidase-like reaction of $\mathrm{Pt}_{600}-\mathrm{GLP}$ NCs. Since the DA molecule has certain reducibility, it will cause the blue solution of $\mathrm{Pt}_{600}$-GLP NCs to fade after the DA molecule is added into the reaction system $\mathrm{Pt}_{600}$-GLP NCs $+\mathrm{H}_{2} \mathrm{O}_{2}+\mathrm{TMB}$ [35]. Figure 10a showed the changes of the reaction system solution with a DA concentration of 1 to $250 \mu \mathrm{M}$ in the UV-Vis spectra. As shown in Figure 10b, the absorbance decreased with the increase of DA concentration, indicating that the blue oxTMB gradually became colorless TMB. Figure $10 \mathrm{c}$ showed that $\mathrm{A}_{652 \mathrm{~nm}}$ decreased linearly with DA concentration, and the linear response range of DA concentration was 1 to $100 \mu \mathrm{M}$. The equation of the standard curve of DA detection was $\mathrm{A}=-0.00304 \mathrm{C}_{\mathrm{DA}}+$ $0.44049\left(R^{2}=0.991\right)$. In addition, the limit of detection (LOD) of DA was as low as $0.66 \mu \mathrm{M}$. Compared with other nanoparticles previously reported (Table 2), $\mathrm{Pt}_{600}$-GLP had a wide 
linear concentration and low detection limit. Therefore, Pt-GLP NCs had higher sensitivity than other mimic enzymes in the detection of DA.
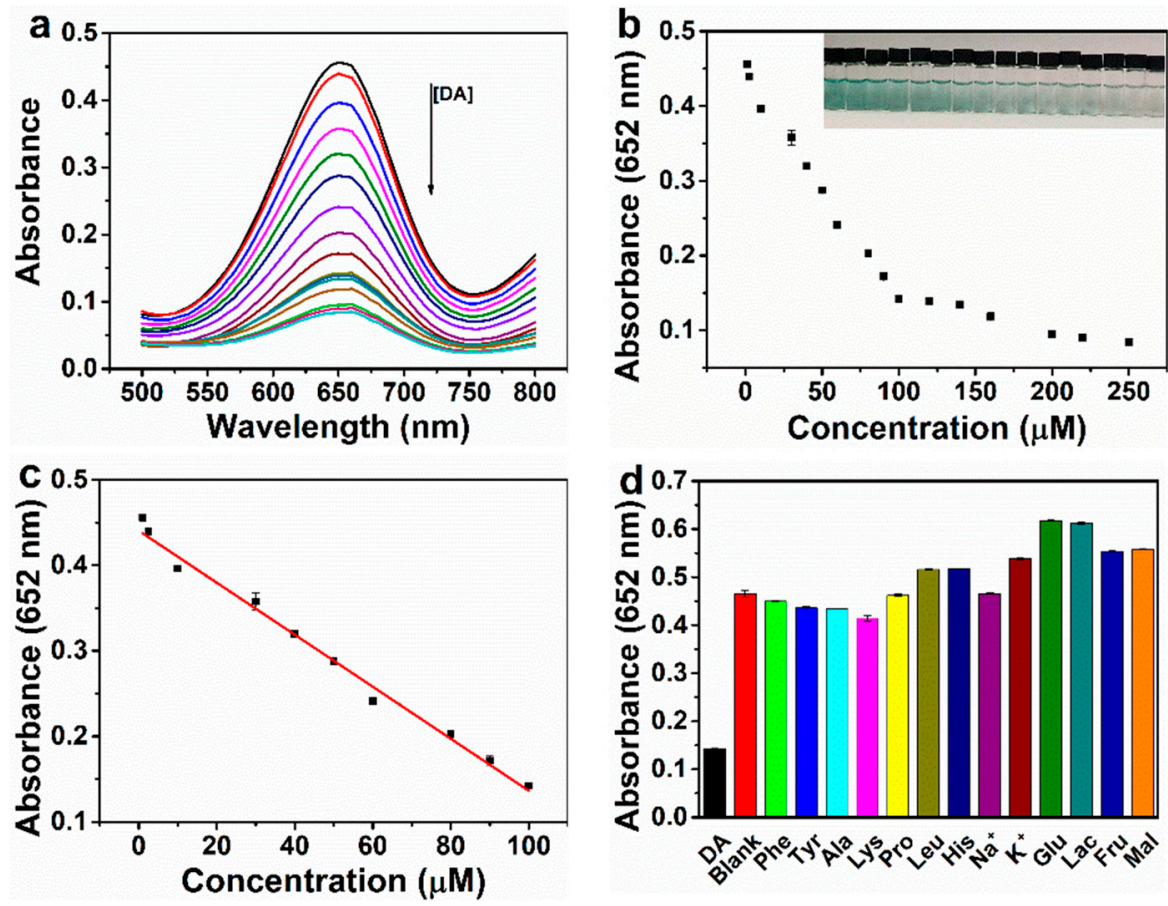

Figure 10. (a) The absorption spectra and (b) absorbance at $652 \mathrm{~nm}$ of mixed solutions when $\mathrm{Pt}_{600^{-}}$ GLP NCs and TMB systems were added by various concentrations of DA (1-250 $\mu \mathrm{M})$, (c) linear calibration chart of DA detection, and $(\mathbf{d})$ the absorbance of dopamine $(100 \mu \mathrm{M})$ and other interfering substances $(1200 \mu \mathrm{M})$.

Table 2. Comparison of the detection of dopamine using $\mathrm{Pt}_{600}-\mathrm{GLP}$ NCs with other reported nanozymes.

\begin{tabular}{ccccc}
\hline Materials & $\begin{array}{c}\text { Linear Range } \\
(\boldsymbol{\mu M})\end{array}$ & $\begin{array}{c}\text { Detection Limit } \\
(\boldsymbol{\mu M})\end{array}$ & Method & Reference \\
\hline $\mathrm{Au}-\mathrm{Cu}_{2} \mathrm{O} / \mathrm{rGO}$ & $10-90$ & 3.9 & Electrochemistry & {$[36]$} \\
$\mathrm{Lac-SBA15}$ & $4-500$ & 4.05 & Electrochemistry & {$[37]$} \\
$\mathrm{GCE} / \mathrm{N}-\mathrm{rGO}-\mathrm{Au}$ & $3-100$ & 2.4 & Electrochemistry & {$[38]$} \\
$\mathrm{WS}{ }_{2} \mathrm{QDs}$ & $3-50$ & 3.3 & Fluorescence & {$[39]$} \\
$\mathrm{ACP}-\mathrm{CDs}$ & $3-20$ & 1 & Fluorescence & {$[40]$} \\
$\mathrm{Pt} / \mathrm{hBNNSs}-5$ & $2-55$ & 0.76 & Colorimetry & {$[11]$} \\
$\mathrm{Pt} / \mathrm{CoSn}(\mathrm{OH})_{6}$ & $5-60$ & 0.76 & Colorimetry & {$[41]$} \\
$\mathrm{Pt}_{600}-\mathrm{GLP} \mathrm{NCs}$ & $1-100$ & 0.66 & Colorimetry & this work \\
\hline
\end{tabular}

In addition, the selectivity of this method was evaluated. From Figure 10d, it could be clearly observed that the absorbance of the $\mathrm{Pt}_{600}$-GLP NCs $+\mathrm{TMB}+\mathrm{H}_{2} \mathrm{O}_{2}$ system was reduced remarkably with the addition of DA. Thus, the system exhibited better selectivity in the detection of DA $(100 \mu \mathrm{M})$ than other interfering substances $(1200 \mu \mathrm{M})$. The interfering substances included phenylalanine, tyrosine, alanine, lysine, proline, leucine, histidine, $\mathrm{Na}^{+}, \mathrm{K}^{+}$, glucose, lactose, fructose, and maltose.

In addition, a standard addition method was used for recovery experiments, in which DA samples with different concentrations were spiked into human serum samples for analysis. As shown in Table 3, the acceptable recovery rate ranged from $96.66 \%$ to $98.80 \%$, and the relative standard deviation was less than $4 \%$. Therefore, this method had a good performance in detecting DA in real samples. 
Table 3. Results for the determination of DA in human serum samples $(n=3)^{1}$.

\begin{tabular}{ccccc}
\hline Sample & Added Amount $(\boldsymbol{\mu M})$ & Found Amount $(\boldsymbol{\mu M})$ & Recovery $(\%)$ & RSD $(\%)$ \\
\hline Serum & 15 & 14.85 & 99.03 & 2.11 \\
Serum & 30 & 28.99 & 96.66 & 1.28 \\
Serum & 45 & 44.46 & 98.80 & 3.23 \\
\hline
\end{tabular}

${ }^{1}$ Dopamine is widely present in the nervous system, and the normal level of DA in serum is between 0.01 and $1 \mu \mathrm{M}$. Since the concentration of DA in the real sample is very low and the amount spiked in the system is very small, the concentration of DA in the initial sample can be considered as zero.

\section{Materials and Methods}

\subsection{Chemicals and Materials}

Ganoderma lucidum was purchased from the local drugstore (Guangyuan, Qinhuangdao in China). Hydrochloric acid ( $\mathrm{HCl})$, acetic acid (HAc), sodium acetate (NaAc), terephthalic acid (TA), sodium hydroxide $(\mathrm{NaOH})$, potassium tetrachloroplatinate (II) $\left(\mathrm{K}_{2} \mathrm{PtCl}_{4}\right)$, 3,3',5,5'-tetramethylbenzidine (TMB), hydrogen peroxide $\left(\mathrm{H}_{2} \mathrm{O}_{2}, 30 \%\right)$, and dopamine hydrochloride (DA) were purchased from Aladdin (Shanghai, China).

\subsection{Extraction of Polysaccharide}

GLP was extracted using the hydrothermal extraction method reported by a previously reported study [42]. The dried Ganoderma lucidum powder was mixed with deionized water at a ratio of 1:50 for water to the powder. The powder was extracted in a $60{ }^{\circ} \mathrm{C}$ constant temperature water bath for $3 \mathrm{~h}$. After extraction, the extract was centrifuged at $4500 \mathrm{rpm}$ for $10 \mathrm{~min}$. Secondly, the supernatant was incubated in a $50{ }^{\circ} \mathrm{C}$ water bath and decolorized with $30 \%$ hydrogen peroxide for $2 \mathrm{~h}$. Then, the extract was deproteinized by the Savage method, and the organic reagents were removed by rotary evaporation. Finally, it was dialyzed with deionized water for $48 \mathrm{~h}$ to obtain GLP after freeze-drying.

\subsection{Determination of Molecular Weight}

The relative molecular weight of polysaccharides was obtained by Shimadzu gel permeation chromatography (GPC, Shimadzu, Kyoto, Japan). The mobile phase was water, the flow rate was $1 \mathrm{~mL} / \mathrm{min}$, the injection volume was $20 \mu \mathrm{L}$, the column temperature was $30^{\circ} \mathrm{C}$, and the chromatographic curve of $1 \mathrm{mg} / \mathrm{mL}$ polysaccharide solution was recorded.

\subsection{Determination of Reducing Power}

One milliliter $(1 \mathrm{~mL})$ polysaccharide solutions with different concentrations were put into a $10 \mathrm{~mL}$ PE tube respectively, and $2.5 \mathrm{~mL}$ phosphate buffer solution at $\mathrm{pH}=6.6$ was added into the PE tube and mixed well. Then, $2.5 \mathrm{~mL} 1 \%$ potassium ferricyanide solution was added. The PE tube was placed in a $50{ }^{\circ} \mathrm{C}$ water bath for $20 \mathrm{~min}$, then removed and quickly cooled, and $2.5 \mathrm{~mL}$ of $10 \%$ trichloroacetic acid was added to the cooled solution and centrifuged at $3000 \mathrm{r} / \mathrm{min}$ for $10 \mathrm{~min}$. In another PE tube, $2.5 \mathrm{~mL}$ of supernatant was added, then $0.5 \mathrm{~mL}$ of $0.1 \%$ ferric chloride and $2.5 \mathrm{~mL}$ of distilled water were also added and mixed well. The absorbance of the solution at $700 \mathrm{~nm}$ was determined by a UV-Vis spectrophotometer (Beijing Purkinje General Instrument Co., Ltd, Beijing, China). In the blank control group, deionized water was used instead of polysaccharide solution, and the above steps were repeated. The reducing power was calculated by sample absorbance minus control absorbance.

\subsection{Purity Determination}

The protein content in the extracted polysaccharide was obtained by the Coomassie Brilliant Blue G-250 (Aladdin, Shanghai, China) staining method. In short, $1 \mathrm{mg} / \mathrm{mL}$ protein solution was prepared as the standard solution and then diluted into different concentrations. The Coomassie brilliant blue G-250 reagent was then added to each solution and thoroughly mixed. After standing for $5 \mathrm{~min}$, the absorbance of the solution at 
$595 \mathrm{~nm}$ was measured by using a UV-Vis spectrophotometer. Thus, the standard curve between absorbance and protein concentration was determined. The absorbance of extracted polysaccharide solution was measured at $595 \mathrm{~nm}$, and the protein content was calculated according to the standard curve.

\subsection{Synthesis and Characterizations of $P t_{n}-G L P N C s$}

GLP solution $(1 \mathrm{mg} / \mathrm{mL})$ was incubated with $\mathrm{K}_{2} \mathrm{PtCl}_{4}(1 \mathrm{mM})$ at $60{ }^{\circ} \mathrm{C}$ for $12 \mathrm{~h}$. The molar ratios of $\mathrm{K}_{2} \mathrm{PtCl}_{4}$ and GLP solution were 600:1, 1000:1, and 1400:1, respectively. Then, the reaction solution was dialyzed in deionized water for $24 \mathrm{~h}$. Different ratios of $\mathrm{Pt}_{\mathrm{n}}-\mathrm{GLP}$ NCs $(n=600,1000$, and 1400) were obtained.

All the UV-Vis measurements were carried out using a UV-TU1810PC spectrophotometer (Beijing Purkinje General Instrument Co., Ltd, Beijing, China). The incubation equipment was a Thermo Shaker (MSC-100) (Hangzhou, China). The size of Pt NCs was evaluated by transmission electron microscopy (TEM, JEM-1230EX, Hitachi, Tokyo, Japan). Dynamic light scattering (DLS, Malvern, Worcestershire, UK) was used to determine the hydrodynamic size and zeta potential of samples.

\subsection{Measurements for the Peroxidase-Like Catalytic Activity}

To perform the catalytic reaction, $50 \mu \mathrm{L} \mathrm{Pt}_{600}-\mathrm{GLP} N C s\left(\mathrm{C}_{\mathrm{Pt}}=0.78 \mathrm{mM}\right)$ were incubated at $25^{\circ} \mathrm{C}$ for $3 \mathrm{~min}$ in a $2 \mathrm{~mL}$ PE tube containing $400 \mu \mathrm{L}$ HAc-NaAc buffer (0.2 M, pH 4.0), and $300 \mu \mathrm{L}$ TMB $(0.6 \mathrm{mM})$ as substrate was added for $3 \mathrm{~min}$. Then, $100 \mu \mathrm{L} \mathrm{H}_{2} \mathrm{O}_{2}(0.3 \mathrm{M})$ was added. After reacting for $5 \mathrm{~min}$, the absorption spectra of the mixture were measured. All TMB was dissolved in 0.2 M HAc-NaAc buffer solution.

The catalytic activity of $\mathrm{Pt}_{600}$-GLP NCs under different $\mathrm{pH}(1.0-10.0)$ was evaluated as follows: $100 \mu \mathrm{L}$ of $\mathrm{Pt}_{600}-\mathrm{GLP}$ NCs $(0.78 \mathrm{mM})$ and $300 \mu \mathrm{L}$ of HAc-NaAc buffer (pH 1.0-10.0, $0.2 \mathrm{M})$ were incubated for $3 \mathrm{~min}, 900 \mu \mathrm{L}$ of TMB $(0.6 \mathrm{mM})$ was mixed for $3 \mathrm{~min}$, then $100 \mu \mathrm{L}$ of $\mathrm{H}_{2} \mathrm{O}_{2}(0.3 \mathrm{M})$ was added for $5 \mathrm{~min}$. The absorbance was recorded at $652 \mathrm{~nm}$. Furthermore, the effect of temperature on the catalytic activity was studied by a similar method. Different reaction temperature from 20 to $80{ }^{\circ} \mathrm{C}$ was used to select the most suitable reaction temperature.

\subsection{Kinetic Analysis}

The kinetic measurement of $\mathrm{Pt}_{600}$-GLP NCs was carried out in time scanning mode under optimal conditions by monitoring the absorbance change at $652 \mathrm{~nm}$ on a UV-Vis spectrophotometer. First, $100 \mu \mathrm{L} \mathrm{Pt}_{600}-\mathrm{GLP}$ NCs $\left(\mathrm{C}_{\mathrm{Pt}}=0.78 \mathrm{mM}\right)$ were kept in different volumes of HAc-NaAc buffer solution. Then, a constant $900 \mu \mathrm{L}$ TMB $(0.6 \mathrm{mM})$ or $100 \mu \mathrm{L}$ $\mathrm{H}_{2} \mathrm{O}_{2}(0.3 \mathrm{M})$ was added as a substrate and reacted for 5 min. Finally, after adding different volumes of $\mathrm{H}_{2} \mathrm{O}_{2}(0.3 \mathrm{M})$ or TMB $(0.6 \mathrm{mM})$ solution, the absorbance changes over time were recorded. The Michaelis-Menten constant $\left(K_{m}\right)$ was calculated by the Lineweaver-Burk plot:

$$
\frac{1}{v}=\frac{K_{m}}{V_{\max }} \frac{1}{[S]}+\frac{1}{V_{\max }}
$$

where $v, K_{m}, V_{\text {max }}$, and [S] represent the initial velocity, Michaelis constant, the maximal reaction velocity, and the concentration of the substrate, respectively.

\subsection{Mechanism Detection}

To study the peroxidase-like enzymatic mechanism of $\mathrm{Pt}_{600}-\mathrm{GLP}$ NCs, terephthalic acid (TA) was used as a fluorescent probe (Hitachi, Tokyo, Japan) to specifically capture the hydroxyl radicals $(\bullet \mathrm{OH})$ possibly generated. Typically, in the PE tube, $900 \mu \mathrm{L}$ of terephthalic acid $(0.5 \mathrm{mM})$ solution and $500 \mu \mathrm{L}$ of sodium acetate buffer $(0.2 \mathrm{M}, \mathrm{pH} 4.0)$ were added. Next, the reaction was carried out in a Thermo Shaker at $40{ }^{\circ} \mathrm{C}$ for $3 \mathrm{~min}$. Then, $100 \mu \mathrm{L} \mathrm{Pt}_{600}-\mathrm{GLP} N C s\left(\mathrm{C}_{\mathrm{Pt}}=0.78 \mathrm{mM}\right)$ was added and the reaction continued for $3 \mathrm{~min}$. After adding $100 \mu \mathrm{L} \mathrm{H}_{2} \mathrm{O}_{2}(0.3 \mathrm{M})$ for $12 \mathrm{~h}$, the final fluorescence of the solution was 
measured. The final concentrations of $\mathrm{TA}, \mathrm{H}_{2} \mathrm{O}_{2}$, and Pt were $0.3 \mathrm{mM}, 20 \mathrm{mM}$, and $49 \mu \mathrm{M}$, respectively.

\subsection{Dopamine Detection}

For DA detection, $\mathrm{Pt}_{600}-\mathrm{GLP} N C s\left(100 \mu \mathrm{L}, \mathrm{C}_{\mathrm{Pt}}=0.78 \mathrm{mM}\right)$ was added into a solution containing TMB $(0.6 \mathrm{mM})$ and $\mathrm{H}_{2} \mathrm{O}_{2}(6 \mathrm{mM})$. After $5 \mathrm{~min}$, different amounts of DA were added to the solution. After another $5 \mathrm{~min}$, the absorbance at $652 \mathrm{~nm}$ was recorded by spectroscopic measurements.

For evaluating the selectivity of the colorimetric method, some typical interfering agents such as phenylalanine, tyrosine, alanine, lysine, proline, leucine, histidine, $\mathrm{Na}^{+}$, $\mathrm{K}^{+}$, glucose, lactose, fructose, maltose $(1200 \mu \mathrm{M})$, and dopamine $(100 \mu \mathrm{M})$ were further investigated.

The effectiveness of dopamine was tested by measuring the recovery. First, the serum was collected by centrifugation. Secondly, the $1 \mu \mathrm{L}$ serum solution was mixed with DA of different concentrations $(15,30,45 \mu \mathrm{M})$ to obtain the sample solution to be tested. Finally, the absorbance at $652 \mathrm{~nm}$ was recorded by the established method.

\section{Conclusions}

In summary, GLP was used as a reducing agent and stabilizer to synthesize platinum nanoclusters. The size of $\mathrm{Pt}$ NCs inside $\mathrm{Pt}_{\mathrm{n}}$-GLP NCs ranged from 1.10 to $2.88 \mathrm{~nm}$. Pt $\mathrm{t}_{\mathrm{n}}-\mathrm{GLP}$ NCs had the peroxidase-like catalytic activity. The best conditions for catalytic activity were $\mathrm{pH} 4.0$ and temperature $50^{\circ} \mathrm{C}$. The catalytic kinetic process of $\mathrm{Pt}_{600}-\mathrm{GLP}$ NCs conformed to the typical Michaelis-Menten equation, and their affinity for both substrates was bigger than that of HRP. Their catalytic process conformed to the ping-pong mechanism. Using the peroxidase activity exhibited by $\mathrm{Pt}_{\mathrm{n}}$-GLP NCs, a colorimetric method for dopamine detection was established. The linear range of the detection method was 1-100 $\mu \mathrm{M}$, and the detection limit was $0.66 \mu \mathrm{M}$. Therefore, the DA concentration can be quantitatively detected by the colorimetric method, which had advantages of a wide detection range, low detection limit, and high selectivity of DA. This method provides a new application of $\mathrm{Pt}_{\mathrm{n}}$-GLP NCs in bio-related detection.

Supplementary Materials: The following are available online, Figure S1: TEM image and histogram of $\mathrm{Pt}_{1000}$-GLP NCs and $\mathrm{Pt}_{1400}$-GLP NCs.

Author Contributions: X.L.: Investigation, Writing-Original Draft; Y.H.: Investigation, Methodology; J.Z. (Jie Zhang): Writing—Review and Editing; J.Z. (Jinyu Zhang): Writing-Review and Editing; W.L.: Writing—Review and Editing; Z.L.: Writing—Review and Editing; L.W.: Conceptualization, Supervision, Methodology, Writing-Review and Editing. All authors have read and agreed to the published version of the manuscript.

Funding: This research was funded by Natural Science Foundation of Hebei Province, grant number B2017203229, and China Postdoctoral Science Foundation, grant number 2016M601284.

Institutional Review Board Statement: All subjects gave their informed consent for inclusion before they participated in the study. The study was conducted in accordance with the Declaration of Helsinki, and the protocol was approved by the Yanshan University Ethics Committee.

Informed Consent Statement: Not applicable.

Data Availability Statement: The data presented in this study are available on request from the corresponding author.

Conflicts of Interest: All authors declare that they have no conflict of interest in this work. 


\section{References}

1. Kumar, S.; Singh, R. Recent optical sensing technologies for the detection of various biomolecules: Review. Opt. Laser. Technol. 2021, 134, 106620. [CrossRef]

2. Chang, Y.; Chen, Y.; Shao, Y.; Li, B.; Wu, Y.; Zhang, W.; Zhou, Y.; Yu, Z.; Lu, L.; Wang, X.; et al. Solid-phase microextraction integrated nanobiosensors for the serial detection of cytoplasmic dopamine in a single living cell. Biosens. Bioelectron. 2021, 175, 112915. [CrossRef] [PubMed]

3. Suzuki, Y. Development of fluorescent reagent based on ligand exchange reaction for the highly sensitive and selective detection of dopamine in the serum. Sensors 2019, 19, 12. [CrossRef]

4. Rasheed, P.A.; Lee, J.-S. Recent advances in optical detection of dopamine using nanomaterials. Microchim. Acta 2017, 184, 1239-1266. [CrossRef]

5. Zhang, L.; Hou, Y.; Lv, C.; Liu, W.; Zhang, Z.; Peng, X. Copper-based metal-organic xerogels on paper for chemiluminescence detection of dopamine. Anal. Methods 2020, 12, 4191-4198. [CrossRef] [PubMed]

6. Fakhri, N.; Salehnia, F.; Beigi, S.M.; Aghabalazadeh, S.; Hosseini, M.; Ganjali, M.R. Enhanced peroxidase-like activity of platinum nanoparticles decorated on nickel- and nitrogen-doped graphene nanotubes: Colorimetric detection of glucose. Microchim Acta 2019, 186, 1-9. [CrossRef]

7. Jiao, A.; Xu, L.; Tian, Y.; Cui, Q.; Liu, X.; Chen, M. $\mathrm{Cu}_{2} \mathrm{O}$ nanocubes-grafted highly dense Au nanoparticles with modulated electronic structures for improving peroxidase catalytic performances. Talanta 2021, 225, 121990. [CrossRef]

8. Rahimi-Nasrabadi, M.; Mizani, F.; Hosseini, M.; Keihan, A.H.; Ganjali, M.R. Detection of hydrogen peroxide and glucose by using $\mathrm{Tb}_{2}\left(\mathrm{MoO}_{4}\right)_{3}$ nanoplates as peroxidase mimics. Spectrochim. Acta Part A Mol. Biomol. Spectrosc. 2017, 186, 82-88. [CrossRef] [PubMed]

9. Hu, Z.; Dai, Z.; Hu, X.; Chen, K.; Gao, C.; Zheng, X.; Yu, Y. Synthesis of PB@FePt hybrid nanoparticles with peroxidase-mimicking activity for colorimetric determination of hydrogen peroxide in living cells. Anal. Methods 2019, 11, 677-683. [CrossRef]

10. Dong, L.; Li, R.; Wang, L.; Lan, X.; Sun, H.; Zhao, Y.; Wang, L. Green synthesis of platinum nanoclusters using lentinan for sensitively colorimetric detection of glucose. Int. J. Biol. Macromol. 2021, 172, 289-298. [CrossRef]

11. Ivanova, M.N.; Grayfer, E.D.; Plotnikova, E.E.; Kibis, L.S.; Darabdhara, G.; Boruah, P.K.; Das, M.R.; Fedorov, V.E. Pt-decorated boron nitride nanosheets as artificial nanozyme for detection of dopamine. ACS Appl. Mater. Interfaces 2019, 11, 22102-22112. [CrossRef]

12. Fan, L.; Ji, X.; Lin, G.; Liu, K.; Chen, S.; Ma, G.; Xue, W.; Zhang, X.; Wang, L. Green synthesis of stable platinum nanoclusters with enhanced peroxidase-like activity for sensitive detection of glucose and glutathione. Microchem. J. 2021, 166, 106202. [CrossRef]

13. Wu, R.; Chong, Y.; Fang, G.; Jiang, X.; Pan, Y.; Chen, C.; Yin, J.-J.; Ge, C. Synthesis of Pt hollow nanodendrites with enhanced peroxidase-like activity against bacterial infections: Implication for wound healing. Adv. Funct. Mater. 2018, 28, 1801484.11801484.11.

14. Kang, Z.W.; Kankala, R.K.; Chen, B.Q.; Fu, C.P.; Wang, S.B.; Chen, A.Z. Supercritical fluid-assisted fabrication of manganese (III) oxide hollow nanozymes mediated by polymer nanoreactors for efficient glucose sensing characteristics. ACS Appl. Mater. Interfaces 2019, 11, 28781-28790. [CrossRef]

15. Cong, C.; Bian, K.; Zhang, X.; Luo, L.; Li, L.; He, H.; Li, C.; Zhao, Q.; Wang, S.; Hao, Z.; et al. Sensitive measurement of tumor markers somatostatin receptors using an octreotide-directed Pt nano-flakes driven electrochemical sensor. Talanta 2020, 208, 120286. [CrossRef] [PubMed]

16. Jin, L.; Meng, Z.; Zhang, Y.; Cai, S.; Zhang, Z.; Li, C.; Shang, L.; Shen, Y. Ultrasmall Pt nanoclusters as robust peroxidase mimics for colorimetric detection of glucose in human serum. ACS Appl. Mater. Interfaces 2017, 9, 10027-10033. [CrossRef] [PubMed]

17. Wang, Z.; Yang, X.; Yang, J.; Jiang, Y.; He, N. Peroxidase-like activity of mesoporous silica encapsulated Pt nanoparticle and its application in colorimetric immunoassay. Anal. Chim. Acta 2015, 862, 53-63. [CrossRef] [PubMed]

18. Velmurugan, P.; Shim, J.; Kim, K.; Oh, B.T. Prunus x yedoensis tree gum mediated synthesis of platinum nanoparticles with antifungal activity against phytopathogens. Mater. Lett. 2016, 172, 61-65. [CrossRef]

19. Syed, A.; Ahmad, A. Extracellular biosynthesis of platinum nanoparticles using the fungus Fusarium oxysporum. Colloids Surfaces B 2012, 97, 27-31. [CrossRef] [PubMed]

20. Lu, J.; He, R.; Sun, P.; Zhang, F.; Linhardt, R.J.; Zhang, A. Molecular mechanisms of bioactive polysaccharides from Ganoderma lucidum (Lingzhi), a review. Int. J. Biol. Macromol. 2020, 150, 765-774. [CrossRef] [PubMed]

21. Ryu, D.H.; Cho, J.Y.; Bin Sadiq, N.; Kim, J.-C.; Lee, B.; Hamayun, M.; Lee, T.S.; Kim, H.S.; Park, S.H.; Nho, C.W.; et al. Optimization of antioxidant, anti-diabetic, and anti-inflammatory activities and ganoderic acid content of differentially dried Ganoderma lucidum using response surface methodology. Food Chem. 2021, 335, 127645. [CrossRef] [PubMed]

22. Cao, W.; Ju, P.; Wang, Z.; Zhang, Y.; Zhai, X.F.; Jiang, F.H.; Sun, C.J. Colorimetric detection of $\mathrm{H}_{2} \mathrm{O}_{2}$ based on the enhanced peroxidase mimetic activity of nanoparticles decorated $\mathrm{Ce}_{2}\left(\mathrm{WO}_{4}\right)_{3}$ nanosheets. Spectrochim. Acta Part A Mol. Biomol. Spectrosc. 2020, 239, 10. [CrossRef] [PubMed]

23. Ferreira, I.C.F.R.; Heleno, S.A.; Reis, F.S.; Stojkovic, D.; Queiroz, M.J.R.P.; Vasconcelos, M.H.; Sokovic, M. Chemical features of Ganoderma polysaccharides with antioxidant, antitumor and antimicrobial activities. Phytochemistry 2015, 114, 38-55. [CrossRef]

24. Zhang, Y.; Feng, Y.; Wang, W.; Jia, L.; Zhang, J. Characterization and hepatoprotections of Ganoderma lucidum Polysaccharides against multiple organ dysfunction syndrome in mice. Oxid. Med. Cell. Longev. 2021, 2021, 9703682. [CrossRef] [PubMed] 
25. Darija, C.R.; Eljko, K.; MaA, K.H.I. Antitumour, antimicrobial, antioxidant and antiacetylcholinesterase effect of Ganoderma lucidum terpenoids and polysaccharides: A review. Molecules 2018, 23, 649.

26. Zhang, H.; Cui, S.W.; Nie, S.-P.; Chen, Y.; Wang, Y.-X.; Xie, M.-Y. Identification of pivotal components on the antioxidant activity of polysaccharide extract from Ganoderma atrum. Bioact. Carbohydr. Diet. Fibre 2016, 7, 9-18. [CrossRef]

27. Pan, D.; Wang, L.; Chen, C.; Teng, B.; Wang, C.; Xu, Z.; Hu, B.; Zhou, P. Structure characterization of a novel neutral polysaccharide isolated from Ganoderma lucidum fruiting bodies. Food Chem. 2012, 135, 1097-1103. [CrossRef] [PubMed]

28. Kang, T.; Kim, Y.G.; Kim, D.; Hyeon, T. Inorganic nanoparticles with enzyme-mimetic activities for biomedical applications. Coord. Chem. Rev. 2020, 403, 213092. [CrossRef]

29. Kora, A.J.; Rastogi, L. Peroxidase activity of biogenic platinum nanoparticles: A colorimetric probe towards selective detection of mercuric ions in water samples. Sens. Actuators B 2018, 254, 690-700. [CrossRef]

30. Cui, T.; Li, S.; Chen, S.; Liang, Y.; Sun, H.; Wang, L. "Stealth" dendrimers with encapsulation of indocyanine green for photothermal and photodynamic therapy of cancer. Int. J. Pharm. 2021, 600, 120502. [CrossRef] [PubMed]

31. Choleva, T.G.; Gatselou, V.A.; Tsogas, G.Z.; Giokas, D.L. Intrinsic peroxidase-like activity of rhodium nanoparticles, and their application to the colorimetric determination of hydrogen peroxide and glucose. Microchim. Acta 2018, 185, 22. [CrossRef] [PubMed]

32. Wu, S.; Zhang, J.; Wu, P. Photo-modulated nanozymes for biosensing and biomedical applications. Anal. Methods 2019, 11, 5081-5088. [CrossRef]

33. Gao, L.; Zhuang, J.; Nie, L.; Zhang, J.; Zhang, Y.; Gu, N.; Wang, T.; Feng, J.; Yang, D.; Perrett, S. Intrinsic peroxidase-like activity of ferromagnetic nanoparticles. Nat. Nanotechnol. 2007, 2, 577-583. [CrossRef]

34. Jin, S.; Wu, C.; Ye, Z.; Ying, Y. Designed inorganic nanomaterials for intrinsic peroxidase mimics: A review. Sensor. Actuat. B Chem. 2019, 283, 18-34. [CrossRef]

35. Wang, J.; Hu, Y.; Zhou, Q.; Hu, L.; Fu, W.; Wang, Y. Peroxidase-like activity of metal-organic framework [Cu(PDA)(DMF)] and Its application for colorimetric detection of dopamine. ACS Appl. Mater. Interfaces 2019, 11, 44466-44473. [CrossRef] [PubMed]

36. Aparna, T.K.; Sivasubramanian, R.; Dar, M.A. One-pot synthesis of $\mathrm{Au}-\mathrm{Cu}_{2} \mathrm{O} / \mathrm{rGO}$ nanocomposite based electrochemical sensor for selective and simultaneous detection of dopamine and uric acid. J. Alloys Compd. 2018, 741, 1130-1141. [CrossRef]

37. Josypcuk, O.; Barek, J.; Josypcuk, B. Amperometric determination of catecholamines by enzymatic biosensors in flow systems Electroanalysis 2018, 30, 1163-1171. [CrossRef]

38. Minta, D.; Gonzalez, Z.; Wiench, P.; Gryglewicz, S.; Gryglewicz, G. N-doped reduced graphene oxide/gold nanoparticles composite as an improved sensing platform for simultaneous detection of dopamine, ascorbic acid, and uric acid. Sensors $\mathbf{2 0 2 0}$ 20, 4427. [CrossRef]

39. Zhao, X.; He, D.; Wang, Y.; Fu, C. Facile fabrication of tungsten disulfide quantum dots (WS ${ }_{2}$ QDs) as effective probes for fluorescence detection of dopamine (DA). Mater. Chem. Phys. 2018, 207, 130-134. [CrossRef]

40. Pan, J.; Miao, C.; Chen, Y.; Ye, J.; Weng, S. Facile fluorescence dopamine detection strategy based on acid phosphatase (ACP) enzymatic oxidation dopamine to polydopamine. Chem. Pharm. Bull. 2020, 68, 628-634. [CrossRef]

41. Liu, H.; Ding, Y.-N.; Bian, B.; Li, L.; Li, R.; Zhang, X.; Liu, Z.; Zhang, X.; Fan, G.; Liu, Q. Rapid colorimetric determination of dopamine based on the inhibition of the peroxidase mimicking activity of platinum loaded $\operatorname{CoSn}(\mathrm{OH})_{6}$ nanocubes. Microchim. Acta 2019, 186, 1-9. [CrossRef] [PubMed]

42. Liu, W.; Xu, J.; Jing, P.; Yao, W.; Gao, X.; Yu, L. Preparation of a hydroxypropyl Ganoderma lucidum polysaccharide and its physicochemical properties. Food Chem. 2010, 122, 965-971. [CrossRef] 